\title{
A Survey to Assess the Job Satisfaction among Health Care Employees
}

\author{
VasanthaKalyani, Dr. Arun K Singhal \\ PhD Scholar, Dr. K N Modi University \\ Professor, Dr. KN Modi University
}

\begin{abstract}
A survey conducted to assess the level of job satisfaction among health care employees who are working in health system. A total no. of 100 employees including professional and non-professional selected as a samples in a purposive sampling technique. The job satisfaction was assessed with the consent for the participation of the study. The job satisfaction and its factors assessed with the help of 3-point scale. The various factors such as recognition at work, leadership relationship, promotion, autonomy ongoing training, benefits and salary were considered for job satisfaction and assessed. The results showed that on overall job satisfaction $60 \%$ of them showed moderately satisfied, 35\% reported satisfied and $5 \%$ reported dissatisfied. On the selected factors autonomy, benefits and salary and recognition at work showed positive relationship with the job satisfaction level.
\end{abstract}

Keywords: job satisfaction, health care employees, health system, survey

\section{Introduction}

In an organization, productivity and quality of service depend entirely on the organization's ability to manage the human resource. Human resource management encompasses organizational development, human resource development, and industrial relations. Human resource functions in an organization include everything that has to do with 'people', i.e., their recruitment, induction, retention, welfare, appraisal, growth, training, skill development, attitudinal-orientation, compensation, motivation, industrial relation and retirement, etc.

All organizations operate within an internal and an external environment. Technology provides resources; structure defines the formal relationship of people in organization and both internal and external environment as well as influences the attitudes of people.

The key to effective work performance is in understanding what domains of work are important for job satisfaction among clinicians.

The job satisfaction of an employee is a topic that has received considerable attention by researchers and managers alike. The most important information to have regarding an employee in an organization is a validated measure of his or her level of job satisfaction (Roznowski and Hulin 1992).[4] Thus, it is fruitful to say that managers, supervisors, human resource specialists, employees, and citizens in general are concerned with ways of improving job satisfaction.

The foundation of job satisfaction theory was introduced by Maslow with a five-stage hierarchy of human needs, now recognized as the deprivation/gratification proposition. However, much of the job satisfaction research has focused on employees in the private sector.

The motivation to investigate the degree of job satisfaction arises from the fact that a better understanding of employee satisfaction is desirable to achieve a higher level of motivation that is directly associated with patient satisfaction.

Offering the highest quality of health-care services possible to as many people who need them, within a given environment of social, material, financial, and human resources is the main goal of health-care systems and of every single health-care organization or unit within an organization. Achieving this goal requires a committed and high-quality workforce in health-care organizations. Due to the anticipated significant impact of human resources management on the quality of services and its increasing coverage in formalized quality systems, it is essential that a health-care establishment pays attention to the quality of human resources in early stages of development of a quality system. Attending to job satisfaction of staff is then a fundamental component of human resources quality. In particular, many researchers have demonstrated strong positive correlations between job satisfaction of medical staff and patient satisfaction with the services in these healthcare settings.

Organizations' efficiency depends to a large extent on the morale of its employee. Behavioral and social science research suggests that job satisfaction and job performance are correlated. Job satisfaction and morale among medical practitioners is a current concern worldwide. Poor job satisfaction leads to increased physician turnover, adversely affecting medical care job satisfaction. Consequently, by creating an environment 
that promotes job satisfaction, a health-care manager can develop employees who are motivated, productive, and fulfilled. This in turn will contribute to higher quality patient care and patient satisfaction.

Schermerhorn define job satisfaction as the degree to which individuals feel positive or negative about their jobs. It is an attitude or emotional response to one's tasks as well as to the physical and social conditions of the workplace. Job satisfaction is motivational and leads to positive employment relationships and high levels of individual job performance.

According to Locke and Hanne, the definition could be 'the pleasant emotional state which flows from someone realizing his or her motives (values) in the work'. 'Job satisfaction is simply how people feel about their jobs and different aspects of their jobs. It is the extent to which people like (satisfaction) or dislike (dissatisfaction) their job. As it is generally assessed, job satisfaction is an attitudinal variable'.

Job satisfaction can be considered as a global feeling about the job or as a related constellation of attitudes about various aspects or facets of the job. The global approach and the facet approach can be used to get a complete picture of employees' job satisfaction. According to Werner, job satisfaction has five facets, which can be put together to measure a job descriptive index (JDI) as follows:

- The work itself - responsibility, interest, and growth

- Quality of supervision - technical help and social support

- Relationships with co-workers - social harmony and respect

- Promotion opportunities - chances for further advancement

- Pay - adequacy of pay and perceived equity vis-à-vis others

Research tends to divide the characteristics of work into two broad categories: extrinsic variables and intrinsic variables. In 1957, Herzberg et al. made the distinction between the intrinsic rewards from the job and the extrinsic rewards from the job. The intrinsic factors refer to a job's inherent features - people's affective reactions to features integral to the work itself. The extrinsic work factors focus on issues that are external to the job itself, such as pay. The distinction between intrinsic and extrinsic work factors, rewards, motives, needs, etc., remains to be a useful tool in studies of many researchers.

There are important reasons why the researcher should be concerned with job satisfaction. The first is that people deserve to be treated fairly and with respect. Job satisfaction is to some extent a reflection of good treatment. It can also be considered as an indicator of emotional well-being or physiological health. The second reason is that job satisfaction can lead to behavior of employees that affects organizational functioning. Furthermore, job satisfaction can be a reflection of organizational functioning. Differences among organizational units in job satisfaction can be diagnostic of potential trouble spots.

Dissatisfied workers are more likely to provide inferior services, and the physical and mental status and the social functioning of these workers can be affected substantially by the level of their job satisfaction.

Hospital personnel have difficulties in meeting the needs of their patients if their own needs are not met; therefore, hospital managers have responsibilities to both staff and patients.

According to the literature, job satisfaction in health-care organizations is related to many factors: optimal work arrangements; the possibility to participate actively in the decision-making process; effective communication among staff and supervisors; and to be able to express freely one's opinion. Collective problem solving and the attitude of management are also important to the satisfaction of the employees.

Job satisfaction can be increased by attending to motivating factors, such as making work more interesting, requiring more initiative, creativity, and planning. This is especially relevant when budget constraints limit increases to pay and benefits.

Managers who grasp the importance of factors affecting the well-being of staff are more likely to gain improved performance from the various groups of hospital staff. It is of utmost importance to seek the opinions of employees and include them in decision-making and problem-solving processes. This will improve satisfaction among the employees and make them feel that they are part of the organization

\section{Objectives}

- To find the level of satisfaction among health care employees who are working in hospital settings.

- To find the relationship between overall satisfaction and factors responsible for job satisfaction

\section{Materials And Methods}

The present study was conducted among health care employees who are working in hospital settings. Non-experimental approach and descriptive survey design used to assess the level of satisfaction among health care employees who are working in hospital settings...Total 100 employees who are working in hospital selected based on purposive sampling technique. The tool used to identify the satisfaction include, demographic data and Rating scale on satisfaction as aemployee in health care. Data were analysed using frequency, percentage distribution and correlation co-efficient to find the relationship. 
Ethical considerations: By getting the permission and written consent form among health care employees who are working in hospital settings willing to participate are involved in this study. Confidentiality of the information shared was maintained.

\section{Results:}

Table - 1: Frequency and percentage distribution on demographic variables among health care employees $(\mathrm{N}=37)$

Table - 1: Frequency and percentage distribution on demographic variables $(\mathrm{N}=100)$

\begin{tabular}{|l|l|}
\hline Demographic variable & Percentage \\
\hline Age & 37 \\
\hline $21-30$ years & 20 \\
\hline $31-40$ years & 30 \\
\hline 51-50 years & 10 \\
\hline Marital Status & \\
\hline Married & 73 \\
\hline Unmarried & 27 \\
\hline Unit of Work & \\
\hline Medical Ward & 35 \\
\hline Surgical Ward & 23 \\
\hline Combined Area & 42 \\
\hline Work Experience & \\
\hline 6 Months < 2 Years & 41 \\
\hline 2 Years < 4 Years & 43 \\
\hline 5 Years < 10 Years & 16 \\
\hline Education Status & \\
\hline Diploma & 21 \\
\hline Professional & 54 \\
\hline Non- professional & 25 \\
\hline
\end{tabular}

Table - 2: Frequency and percentage distribution on overall job satisfaction among health care employees

\begin{tabular}{|l|l|l|}
\hline Overall satisfaction & Frequency & Percentage \\
\hline Satisfied & 35 & $35 \%$ \\
\hline Moderately satisfied & 60 & $60 \%$ \\
\hline Dissatisfied & 05 & $5 \%$ \\
\hline
\end{tabular}

Table - 3: Frequency and percentage distribution on various factors assessed in job satisfaction among Leadership Relation . health care employees $(\mathrm{N}=100)$

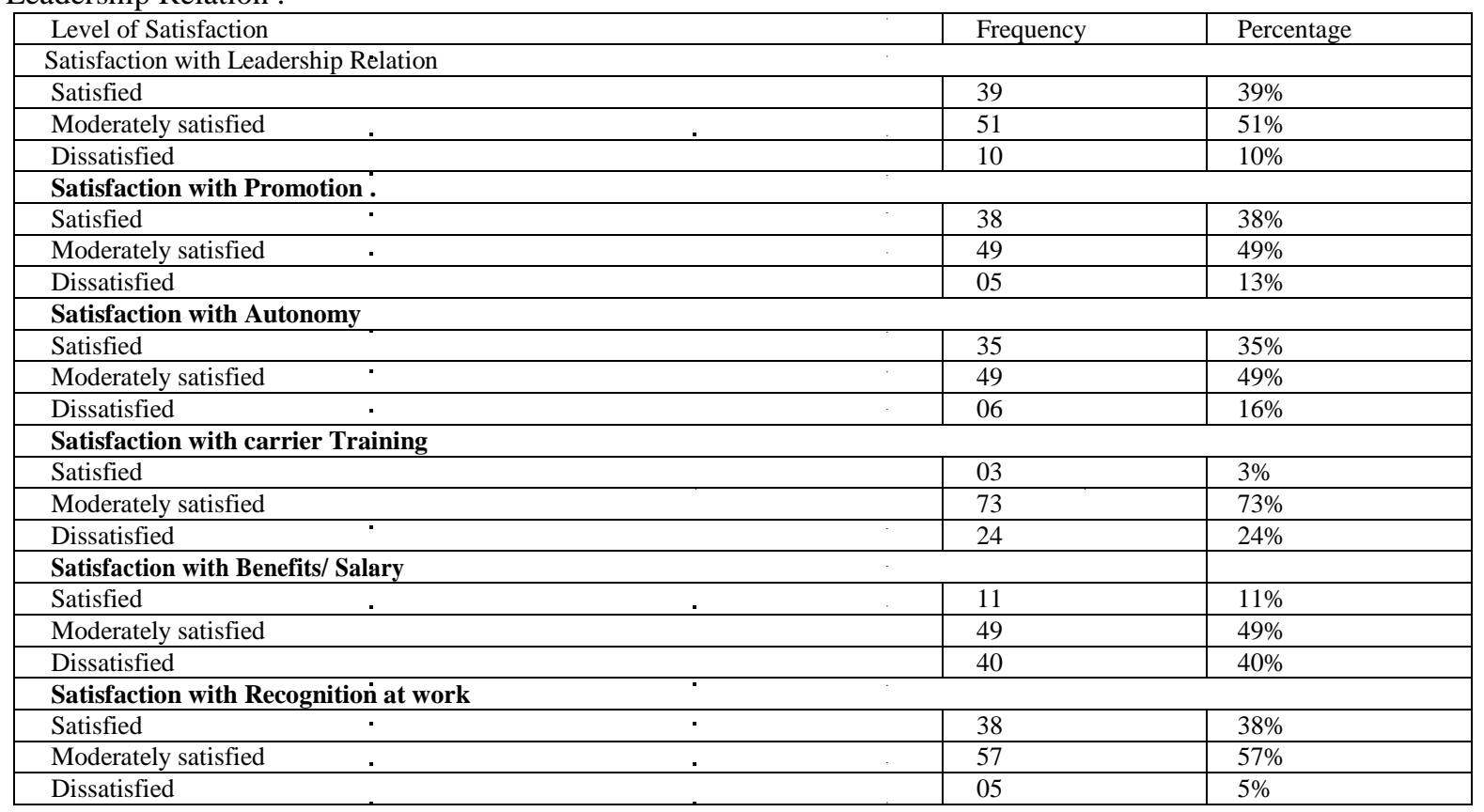


A Survey To Assess The Job Satisfaction Among Health Care Employees

Table - 4: correlation co-efficient between overall job satisfaction and it's factors among health care employees

\begin{tabular}{|l|l|l|}
\hline Factors & Correlation co-efficient & Relationship \\
\hline Leadership relation & $\mathrm{r}=-1$ & Negative \\
\hline Promotion & $\mathrm{r}=-1$ & Negative \\
\hline Autonomy & $\mathrm{r}=1$ & positive \\
\hline Professional training & $\mathrm{r}=-1$ & Negative \\
\hline Benefits \&salary & $\mathrm{r}=1$ & Positive \\
\hline Recognition at work & $\mathrm{r}=1$ & Positive \\
\hline
\end{tabular}

The demographic details of the participants presented in table 1 showed that the participants all(100\%) were in the age group between 20-30 years and most of them were unmarried(76\%).In relation to the unit of work exposed $35 \%$ were in medical ward,23 \% were in surgical ward and $42 \%$ other combined areas. With regard to their years of experience $43 \%$ had $2-4$ years, $41 \%$ had 6 months-2 years and $16 \%$ had $5-10$ years of experience. Regarding their educational status $54 \%$ wereprofessional, $21 \%$ were diploma graduates and $25 \%$ were postgraduates.

The findings of the overall job satisfaction among health care employees presented in table 2 showed that $60 \%$ of the health care employees are moderately satisfied, $35 \%$ of them were satisfied and $5 \%$ of them were dissatisfied with the work. The findings of the level of job satisfaction as per the various factors selected in this study presented in table 3 showed that on the leadership relationship 51\%were moderately satisfied, 39\% were satisfied and $10 \%$ were dissatisfied.

On the promotion $38 \%$ were satisfied, $49 \%$ were moderately satisfied and $13 \%$ were dissatisfied. In the aspect of autonomy $35 \%$ were satisfied, $49 \%$ were moderately satisfied and $16 \%$ were dissatisfied. Regarding professional training only $3 \%$ were satisfied, $73 \%$ were moderately satisfied and $24 \%$ were dissatisfied. In regard of benefits and salary $11 \%$ were satisfied, $49 \%$ were moderately satisfied and $40 \%$ were dissatisfied. On the aspect of recognition at work $38 \%$ were satisfied, $57 \%$ were moderately satisfied and $5 \%$ were dissatisfied. The findings of the correlation co-efficient between the overall satisfaction and each factor of this study. Presented in table 4 showed that the correlation co-efficient on leadership relation, promotion, and professional training showed negative relationship $r=-1$. The factors such as autonomy, benefits \&salary and recognition at work shows positive relationship $\mathrm{r}=1$.

\section{Discussion}

In this present study the health care employees selected were between most of them in the age group of 20-30 years $73 \%$ was married and 54\% completed professional. Among the participants $43 \%$ had 2-4 years of experience and 35\% had experience in medical unit and $42 \%$ combined area of experience. The overall job satisfaction among health care employees as most of them $60 \%$ reported was moderate satisfaction, while checking the various factors influencing job satisfaction in thisstudy, majority of them reported moderate satisfaction in all the factors studied such as leadership, promotion, autonomy and professional training. The professional training and benefits and salary were those two factors most ofthem reported dissatisfied while comparing to other factors. The relationship between the overall satisfaction andother factors showed that there was a positive relationship in autonomy, benefits \& salary and recognition at work.

This findings show that these factors will improve the overall among health care employees.

The study concluded that the health care employees were not satisfied with the benefits and salary and recognition at work as they are dominated by their other senior's staff counterparts. The need for providing a conducive work environment for the employees who are working in hospital and health care sectors will improve the job satisfaction. The leaders in health care systemhas to make policies and regulations that every employee who enters into the health sector should deliver high quality care with full job satisfaction.

\section{References}

[1]. Chad O’Lynn, Men in Nursing: History, Challenges, and Opportunities, Springer publishing company, LLC, Newyork, USA.

[2]. Geraldine Ann Moore, Job satisfaction and career development of men in nursing, Journal of Nursing Education and Practice, 2014, Vol. 4, No. 3, PP 86-93, DOI: 10.5430/jnep.v4n3p86 URL: http://dx.doi.org/10.5430/jnep.v4n3p86.

[3]. M.Lorber,B.S.Savic,'Job satisfaction of nurses and identifying factors of job satisfaction", Cronation medical journal, vol.53(3),pp.263-270.

[4]. AgezegnAsegid, Tefera Belachew, and EbrahimYimam, "Factors Influencing Job Satisfaction and Anticipated Turnover among Nurses in Sidama Zone Public Health Facilities, South Ethiopia," Nursing Research and Practice, vol. 2014, Article ID 909768, 26 pages, 2014. doi:10.1155/2014/909768. 